\title{
Immune mediators in the tumor microenvironment of prostate cancer
}

\author{
Jinlu Dai ${ }^{1}$, Yi Lu² ${ }^{2}$ Hernan Roca ${ }^{3}$, Jill M. Keller ${ }^{1}$, Jian Zhang ${ }^{2}$, Laurie K. McCauley ${ }^{3}$ and Evan T. Keller ${ }^{1,4^{*}}$
}

\begin{abstract}
Prostate cancer tissue is composed of both cancer cells and host cells. The milieu of host components that compose the tumor is termed the tumor microenvironment (TME). Host cells can be those derived from the tissue in which the tumor originates (e.g., fibroblasts and endothelial cells) or those recruited, through chemotactic or other factors, to the tumor (e.g., circulating immune cells). Some immune cells are key players in the TME and represent a large proportion of non-tumor cells found within the tumor. Immune cells can have both anti-tumor and pro-tumor activity. In addition, crosstalk between prostate cancer cells and immune cells affects immune cell functions. In this review, we focus on immune cells and cytokines that contribute to tumor progression. We discuss T-regulatory and T helper 17 cells and macrophages as key modulators in prostate cancer progression. In addition, we discuss the roles of interleukin-6 and receptor activator of nuclear factor kappa-B ligand in modulating prostate cancer progression. This review highlights the concept that immune cells and cytokines offer a potentially promising target for prostate cancer therapy.
\end{abstract}

Keywords: Prostate cancer, Tumor microenvironment, Macrophage, T-regulatory cell, Th17 cell, Interleukin-6, Receptor activator of nuclear factor kappa-B ligand

\section{Background}

Prostate cancer tissues are composed of both tumor cells and host components. Host components consist of soluble factors (e.g., cytokines), stromal matrix, and cells. The milieu of host components in the tumor is termed the tumor microenvironment (TME) [1]. The cellular component of the TME consists of both host cells that are initially presented in a primary or metastatic lesion and cells that are recruited in response to either tumor- or host-derived factors. Most host cells, including stromal cells, vascular cells, and immune cells, may contribute to the function of the TME. Most cancer therapies directly target tumor cells through cytostatic or cytocidal activity. Recently, in addition to strategies targeting tumor cells, strategies targeting the TME have been explored. For example, it has been demonstrated that targeting the vasculature can reduce tumor-associated immunosuppression and thus improve therapeutic effects [2].

\footnotetext{
*Correspondence: etkeller@umich.edu

${ }^{4}$ Department of Urology, University of Michigan, Ann Arbor, MI 48109-8940, USA

Full list of author information is available at the end of the article
}

Accordingly, a thorough understanding of the TME is necessary to develop the most efficacious therapy.

Crosstalk between tumor cells and the TME results in an orchestrated evolution of both the TME and the tumor as the tumor progresses. The TME reacts to prostate cancer cell-produced soluble factors and directly interacts with prostate cancer cells. In return, the TME produces soluble factors, provides structural support, and contacts with cancer cells to influence the establishment and progression of prostate cancer [3]. There are several excellent reviews on tumor-TME crosstalk $[4,5]$. In the current review, we focus on the immune component of the TME that promotes tumor progression.

\section{Inflammatory immune cells}

Inflammation can potentially contribute to prostate cancer pathophysiology through several mechanisms, including generation of reactive oxygen species that lead to mutagenesis; production of cytokines to promote tumor growth and suppress anti-tumor immune response; and enhancement of the migration of tumorpromoting immune cells into the tumor [6, 7]. Immune 
cells compose the cellular arm of the inflammatory response, and in this review, we highlight some of these cells and how they have been thought to contribute to prostate cancer progression (Table 1).

\section{Tumor-modulating $T$ cells and prostate cancer}

Tumor-infiltrating lymphocytes (TILs) contribute to the progression of prostate cancer through multiple mechanisms that have not been well defined yet. One type of TIL, the T-regulatory cell (Treg), has been identified as a primary mediator in cancer progression. Tregs are $\mathrm{CD} 4{ }^{+} \mathrm{T}$ cells that inhibit the activity of $\mathrm{T}$ effector cells; however, specific definitions based on cell surface markers constantly change due to heterogeneity of the Treg population [8]. This constant evolution of defining the Treg phenotype creates a challenge in interpreting the literature, and one must be aware of how the Treg is defined in a particular publication. Tregs tend to suppress antitumor responses rather than promote tumor cell growth directly. In support of the importance of Tregs in prostate cancer, Tregs that were defined as $\mathrm{CD} 4^{+} \mathrm{CD} 25^{\text {high }}$ cells with in vitro immunosuppressive function were found to be increased in prostate cancer tissues compared with non-cancerous prostate tissues [9]. In addition, to determine the phenotype of TILs, Sfanos et al. [10] performed multiple biopsies of prostate cancers and determined the phenotypes of the procured cells by flow cytometry. They found that tumor-infiltrating $\mathrm{CD}_{4}{ }^{+} \mathrm{T}$ cells were skewed toward Treg (FoxP3 ${ }^{+}$, forkhead box P3) and T helper 17 (Th17) phenotypes rather than Th2 phenotype. This finding was extended to the peripheral blood, where the proportions of $\mathrm{CD} 4{ }^{+} \mathrm{CD} 25^{\text {high }}$ Tregs were increased in men with prostate cancer compared with healthy donors [9]. Further studies showed that tumor-infiltrating Tregs, defined as $\mathrm{CD}^{+}{ }^{+} \mathrm{FoxP}^{+}$cells, suppressed naive $\mathrm{T}$ cell proliferation mainly through a cell contact-dependent mechanism [11]. However, the ability to suppress T-cell proliferation may not always result in inhibition of tumorspecific immune activity. In a transgenic adenocarcinoma mouse prostate (TRAMP) model of prostate cancer, $\mathrm{CD} 4{ }^{+} \mathrm{CD} 25^{+} \mathrm{FoxP}^{+}$Tregs were found to be dispensable for induction of tumor-specific tolerance [12]. Yokokawa et al. [13] evaluated levels of CD $4^{+} \mathrm{CD} 25^{\text {high }} \mathrm{FoxP} 3^{+}$Tregs in the peripheral blood of healthy donors and patients with biochemically progressive, localized, or metastatic prostate cancer by flow cytometry. The function of Tregs was determined by their ability to suppress the proliferation of $\mathrm{CD} 4^{+} \mathrm{CD} 25^{-} \mathrm{T}$ cells [13]. They found that although no differences were observed in the amount of Tregs in the peripheral blood among different groups, Tregs from patients with prostate cancer had significantly greater suppressive function than Tregs from healthy donors [13]. In addition to the tumor itself, cancer therapies may also affect Treg functions. For example, androgen modulation is an important and often-used therapy for prostate cancer. In a mouse model, androgen ablation induced a transient increase of $\mathrm{CD}_{4}^{+} \mathrm{T}$ cells and $\mathrm{CD} 8^{+} \mathrm{T}$ cells in residual tumor [14]. More than 2 months later, FoxP3 ${ }^{+}$ Tregs were increasingly found within prostate epithelium, whereas cytotoxic $\mathrm{T}$ lymphocytes, which were evenly distributed before androgen ablation, became sequestered within stroma [14]. Thus, androgen modulation could affect the efficacy of an immunotherapy regimen and should be considered when patients with prostate cancer are treated with immune-dependent regimens. Taken together, these results indicate tumors and tumor therapies can affect Treg function; however, large clinical trials to validate these findings should be performed.

In addition to Tregs, another subset of $\mathrm{CD} 4^{+} \mathrm{T}$ cells, Th17 cells, may affect prostate cancer biology and

Table 1 Summary of key immune cells and cytokines found in the tumor microenvironment of prostate cancer

\begin{tabular}{ll}
\hline Type & Prevalence and function \\
\hline Treg & $\begin{array}{l}\text { Definition is constantly refined; however, FoxP3 is consistently expressed. Highly prevalent in prostate cancer tissues. } \\
\text { Potential roles include immunosuppression, allowing tumors to escape from immunosurveillance }\end{array}$ \\
Th17 cells $\quad$ CD4 ${ }^{+}$T cells that express high levels of IL-17. The number of Th17 cells in tumors inversely associates with tumor \\
grade, and the number of Th17 cells in peripheral blood inversely correlates with time to progression in patients with \\
prostate cancer
\end{tabular}

CCL2 chemokine (C-C motif) ligand-2, IL-6 interleukin-6, IL-17 interleukin-17, RANKL receptor activator of nuclear factor kappa-B ligand, Th17T helper 17, Treg T-regulatory cell, TME tumor microenvironment, FoxP3 forkhead box P3 
responses to immunotherapy. Th17 cells are $\mathrm{CD} 4^{+} \mathrm{T}$ effector cells that produce a large amount of interleukin-17 (IL-17) which is a pro-inflammatory cytokine that attracts and activates granulocytes and monocytes [15]. The role of Th17 cells in cancer is controversial. They have been reported to both inhibit cancer and promote it [16]. An initial clue to the importance of Th17 cells came from an early study which demonstrated that injection of a fusogenic glycoprotein in combination with heat shock protein 70 (HSP70), as an immune adjuvant, induced an anti-tumor T-cell immune response that was associated with increased IL-17 expression [17]. To compare the prognostic implications of the pretreatment level of Th17 cells with those of Tregs in prostate cancer patients who received active whole-cell vaccine-based immunotherapy, Derhovanessian et al. [18] detected the frequencies of Th17 cells and Tregs in the peripheral blood of patients with hormone-resistant non-bone metastatic prostate cancer prior to immunotherapy. They found that the frequency of Th17 cells inversely correlated with time to disease progression. Furthermore, patients who responded to immunotherapy with significant reductions in prostate-specific antigen (PSA) velocity showed a Th17 profile similar to that of healthy men; whereas, those who did not respond had a significantly different Th17 profile compared with that of responders and healthy men [18]. In contrast, although the frequency of Tregs in the peripheral blood was higher in men with prostate cancer than in age-matched healthy men, no difference was observed between responders and nonresponders [18]. These data indicated that Th17 cells may predict therapeutic response to active whole-cell vaccinebased immunotherapy. The true role that Th17 cells play in prostate cancer (i.e., inhibit or promote prostate cancer progression) may depend on tumor stage. Additional research efforts should be devoted to this concept.

\section{Macrophages and prostate cancer}

Macrophages have been found to play intriguing roles in promoting tumor progression. Among bone marrowderived cells in the TME, macrophages are one type of these cells that significantly associate with tumor progression and immunosuppression [19-23]. It has been well recognized that macrophages infiltrate the tumor tissue (these macrophages are termed tumor-associated macrophages [TAMs]); moreover, for prostate cancer, more macrophages were observed in metastatic nodules than in primary tumors [24]. The increase of TAMs in prostate cancers may be mediated through prostate cancer-derived parathyroid hormone-related protein (PTHrP) which has been shown to recruit myeloid cells via osteoblast-produced chemokine ( $\mathrm{C}-\mathrm{C}$ motif) ligand 2 (CCL2) [25]. Although an increase of TAMs in prostate cancers is well recognized, little is known about the specific mechanisms by which macrophages promote tumor growth.

A primary role of macrophages is phagocytosis during bacterial infection [26], yet phagocytosis is an often overlooked function relative to tumorigenesis [27, 28]. Efferocytosis refers to the specific phagocytosis of apoptotic cells and is an integral process in tissue homeostasis, inflammation, and autoimmunity [29]. Like many other tumor-promoting activities, efferocytosis is a physiologic activity that may be hijacked by tumors to benefit their establishment and growth.

Macrophages perform efferocytosis via distinct receptor signaling pathways [30]. Specific "eat me" signal molecules, such as milk fat globule-E8 (MFG-E8), are expressed by activated macrophages and bridge apoptotic cells and macrophages to facilitate efferocytosis [31-33]. MFG-E8 includes the $\mathrm{N}$-terminus that bears a signal peptide to direct secretion, an epidermal growth factor (EGF)-repeated domain that contains an Arg-Gly-Asp (RGD) motif for recognition of integrin on phagocytic cells, and the C-terminus that bears a factor V/VIII-like domain enabling binding to phosphatidylserine in apoptotic cells [33]. MFG-E8 is produced by several types of cells, most notably macrophages, and co-localizes with the activated marker CD68 [34]. The majority of research on MFG-E8 has been performed in the mammary gland, where it was originally identified, as well as in the peritoneal cavity, spleen, and lung [34]. In patients with triplenegative breast cancer, MFG-E8 promotes breast cancer progression through the p63 pathway; but in estrogen receptor- and erbB2-positive breast cancers, MFG-E8 serves a suppressive function [35]. In the context of prostate cancer bone metastasis, TAMs are polarized upon interaction with apoptotic tumor cells in an MFG-E8-dependent manner that supports tumor progression [36], similar to that observed in triple-negative breast cancer [35]. In the bone microenvironment, factors released by efferocytic macrophages could increase the resistance of bone metastases to cancer therapies, resulting in a lack of therapeutic response or reduced response duration. MFG-E8 and other intra- and extra-cellular signaling events specifically related to macrophage-mediated efferocytosis represent intriguing new pharmacologic targets for patients with bone metastasis.

\section{Cytokines and prostate cancer}

A variety of cytokines are secreted by cells in the TME that can affect prostate cancer growth. These cytokines can act in a paracrine fashion on tumor cells to stimulate a variety of tumor activities, including proliferation, chemoresistance, anti-apoptosis, migration, and invasion. In this review, we focus on two immune-related 
cytokines, interleukin-6 (IL-6) and receptor activator of nuclear factor kappa-B ligand (RANKL), that are expressed in the TME of prostate cancer.

\section{IL-6}

IL-6 is produced by inflammatory cells and osteoblasts and has ample opportunities to interact with prostate cancer cells [37]. A great deal of clinical and experimental evidence suggests that IL-6 promotes prostate cancer progression [38]. Several studies have shown that IL-6 level is elevated in the sera of patients with metastatic prostate cancer [39-41]. For example, Alcover et al. [40] assessed serum levels of IL-6 and its soluble receptor to determine if these levels could be used to predict biochemical recurrence in patients who underwent radical prostatectomy. They found that preoperative serum levels of IL-6 higher than $1.2 \mathrm{pg} / \mathrm{mL}$ in men with prostate cancer were associated with an increased probability of biochemical recurrence (i.e., increased serum PSA levels) [40]. Although the study had a small sample size, the results support further evaluation of IL-6 as a prognostic factor. Similarly, Stark et al. [41] proved that pre-diagnostic IL-6 level was associated with time to progression/ death for prostate cancer patients with healthy weight. Overall, the preponderance of evidence suggests that IL-6 level is elevated in men with prostate cancer and is related to the clinical outcome of prostate cancer.

In addition to these clinical observations, in vitro cellular studies have shown that IL- 6 modulates the growth of prostate cancer cells. Chung et al. [42] showed that IL-6 promoted the growth of hormone-refractory cells but had no effect on hormone-dependent cell lines. Some studies have reported that the addition of exogenous IL- 6 to the culture media of prostate cancer LNCaP cells resulted in a dose-dependent growth inhibition with neuroendocrine differentiation [43, 44], whereas in other instances, cell proliferation was increased [42-48]. The reasons for these differences have not yet been clarified, and it appeared that IL- 6 inhibited the growth of only LNCaP cells but not other prostate cancer cell lines [49].

In addition to increased proliferation, decreased apoptosis can also promote tumor growth. IL-6 has an antiapoptotic effect on many types of cancer cells, including prostate cancer cells $[50,51]$. A previous study demonstrated that orchiectomy induced a conversion of $\mathrm{LuCaP}$ 35 tumors to an androgen-independent phenotype through increased IL-6 expression [52]. It has been shown that targeting IL- 6 with an IL- 6 antibody promoted the apoptosis of androgen-independent PC-3 cells in mice [53]. IL-6 protects prostate cancer cells against apoptosis through activation of signal transducer and activator of transcription 3 (STAT3) [50] and phosphatidylinositol-3 kinase (PI3K) [51]. Taken together, decreased proliferation and increased apoptosis caused by inhibiting IL-6 suggest that IL-6 coordinates both processes to promote the growth of androgen-independent tumors.

In addition to the effect of enhancing cell proliferation, IL-6 also enhances other aspects of prostate cancer. For example, IL-6-mediated activation of STAT3 activates insulin-like type I growth factor receptor (IGF-IR), resulting in tumorigenesis [54]. IL-6 is also associated with neuroendocrine differentiation of prostate cancer cells [44]. In combination with the cytokine CCL2, IL-6 induces M2-type macrophage polarization and promotes $\mathrm{CD}_{11 \mathrm{~b}}{ }^{+}$peripheral blood mononuclear cell survival [55]. Together, these findings indicate that IL- 6 contributes to prostate cancer progression through multiple activities.

The above published studies suggesting the contribution of IL- 6 to prostate cancer progression provided the rationale for a clinical trial to evaluate IL-6-targeted therapies. A human-mouse chimeric monoclonal neutralizing IL-6 antibody (siltuximab, also known as CNTO 328) has been evaluated in a phase II study in men with advanced castration-resistant prostate cancer, with PSA response rate being the primary endpoint [56]. However, the response rate was only $3.8 \%$, and no men with measurable disease had a response according to the Response Evaluation Criteria in Solid Tumors (RECIST); even so, C-reactive protein, an indicator of IL-6 activity, was decreased, suggesting that IL- 6 was effectively neutralized [56]. These results suggest that targeting IL-6 in men with advanced castration-resistant disease may not result in a significant direct anti-tumor benefit. In contrast to a direct anti-tumor effect, IL-6 has an anti-apoptotic effect [57], suggesting a possibility that targeting IL-6, which would block the anti-apoptotic effect of IL-6, may synergize with a chemotherapy regimen by promoting cell death.

\section{RANKL}

RANKL is expressed on the surface of activated $\mathrm{T}$ cells and interacts with its receptor, receptor activator of nuclear factor kappa-B (RANK), on dendritic cells (DCs) to promote the survival of DCs and increase their activities as antigen-presenting cells [58]. In addition to its direct immune function, RANKL promotes osteoclastogenesis. It has been identified that osteocytes also produce RANKL in the bone microenvironment [59]. RANKL can be expressed as a membrane-bound molecule or, in some instances, be cleaved to form a functional soluble RANKL peptide [60]. RANKL binds to the transmembrane receptor RANK on osteoclast precursors and initiates osteoclastogenesis [61, 62]. It has been demonstrated that RANKL and RANK are required 
for osteoclastogenesis since transgenic rankl $\mathrm{ra}^{-1-}$ and rank $^{-1-}$ mice had no osteoclasts or developed osteosclerotic bones [63, 64]. Osteoprotegrin (OPG) is a soluble glycoprotein that negatively regulates osteoclastogenesis through sequestering RANKL, resulting in the block of its interaction with RANK [65]. Thus, the balance between RANKL and OPG determines the extent of bone resorption.

Many cancers found in the skeleton [66], including osteoclastomas [67] and prostate cancer bone metastases [68], have dysregulated RANKL, OPG, or RANK expression. Both prostate cancer epithelium and stromal cells express RANKL [68], whose level directly associates with disease stage [69] and may have a prognosis-predictive value [70]. Prostate cancer cells initiate osteoclastogenesis through RANKL $[71,72]$. In murine models of prostate cancer bone metastasis, using OPG [71] or soluble RANK [73] to inhibit RANKL activity decreased both the amount of mature osteoclasts and the frequency of bone lesions. The decrease of tumor-induced bone destruction is associated with decreased pain-associated behaviors in murine models of bone cancer [74, 75]. Taken together, these findings suggest that inhibiting RANKL will diminish both tumor-associated bone remodeling and bone pain.

In addition to its effect on bone remodeling, RANKL has direct effects on cancer cells. For example, RANKL binds with RANK on prostate cancer cells and then induces pro-metastatic gene expression, resulting in increased invasive ability of prostate cancer cells [76]. Furthermore, inhibition of RANKL by OPG promotes prostate cancer cell survival through inhibition of TNFrelated apoptosis-inducing ligand (TRAIL)-mediated apoptosis [77]. These findings, in combination with the reports of tumor-mediated bone resorption via RANKL, indicate that targeting RANKL would have a two-pronged therapeutic effect by inhibiting both tumorinduced bone resorption and pro-metastatic activity of tumor, which have provided the rationale to evaluate the clinical efficacy of targeting RANKL in cancer-related bone diseases.

The anti-tumor effect of denosumab, a human monoclonal IgG2 antibody that targets RANKL, has been evaluated in several clinical trials. Denosumab reduced the expression of urinary $\mathrm{N}$-telopeptides of collagen (uNTx), a biomarker for osteoclast activity, in a phase II study that included patients with prostate cancer bone metastases [78]. In another clinical trial, bone mineral density (BMD) was significantly improved compared with baseline after treatment with denosumab in men with prostate cancer who were being treated with androgen-deprivation therapy $[79,80]$. Also in a clinical trial, zoledronic acid (an anti-osteoclastic bisphosphonate) was compared with denosumab for prevention of skeletal-related events (SREs: defined as presence of bone fracture, need for bone pain palliation, or need for bone surgery) in men with castration-resistant prostate cancer and bone metastases [81]. Denosumab significantly delayed the time to first on-study SRE as well as the time to first and subsequent on-study SRE compared with zoledronic acid [81]. The above studies and additional preclinical and clinical data $[82,83]$ have supported the United States Food and Drug Administration approval of denosumab for treating patients with prostate cancer (and breast cancer) bone metastases.

\section{Conclusions and future directions}

Multiple host factors in the TME contribute to prostate cancer progression (Fig. 1; Table 1). Immune cells, such as Tregs, Th17 cells, and macrophages, are major modulators of prostate cancer progression. In addition, host cells affect prostate cancer cells via cytokines. Cytokines such as IL-6 and RANKL have pleiotropic actions on prostate cancer cells. These findings show that the TME offers potentially promising targets for prostate cancer therapy. Further studies on host immune factors, in addition to studies on tumors, may validate their potential therapeutic benefits.

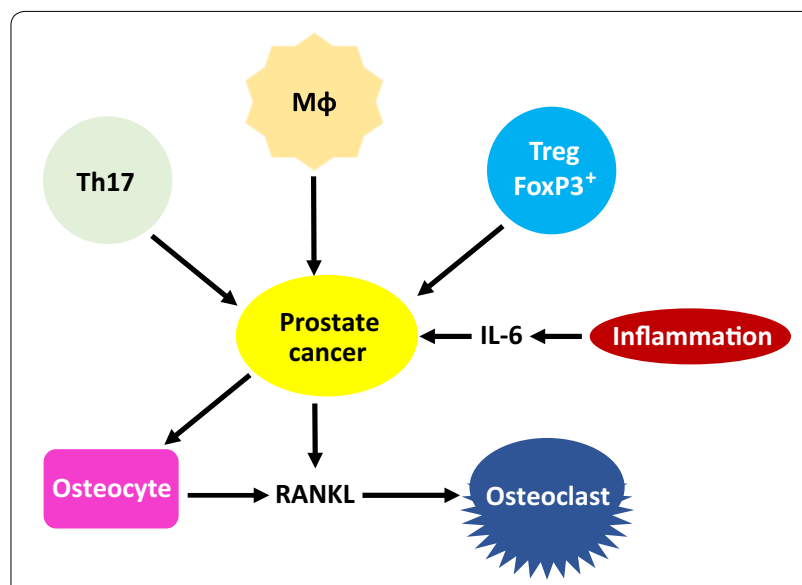

Fig. 1 Key immune cells and cytokines in the tumor microenvironment of prostate cancer. Tregs suppress the activation of anti-tumor T cells to promote tumor progression. Th17 cells may promote or inhibit prostate cancer progression depending on the context. Macrophages promote prostate cancer growth through efferocytosis. Inflammatory stimuli can lead to IL-6 production, which, in turn, can promote prostate cancer growth. Prostate cancer cells can produce RANKL directly and stimulate host cells (e.g., osteocytes) to produce RANKL in the tumor microenvironment. RANKL can then mediate tumor-induced bone remodeling through osteoclast activation. IL-6 interleukin-6, $M \phi$ macrophage, RANKL receptor activator of nuclear factor kappa-B ligand, Th17T helper 17, Treg T-regulatory cell, FoxP3 forkhead box P3 


\section{Authors' contributions}

All authors contributed to drafting the mansucript. All authors approved the final mansucript.

\section{Author details}

${ }^{1}$ Department of Urology and Biointerfaces Institute, University of Michigan, Ann Arbor, MI 48109, USA. ${ }^{2}$ Center for Translational Medicine, Guangxi Medical University, Nanning, Guangxi 520021, P. R. China. ${ }^{3}$ Periodontics and Oral Medicine, School of Dentistry, University of Michigan, Ann Arbor, Ml 48109, USA. ${ }^{4}$ Department of Urology, University of Michigan, Ann Arbor, MI 48109-8940, USA

\section{Acknowledgements}

This work was supported by National Cancer Institute Grants (Nos. P01 CA093900 and R01 CA190554); National Natural Science Foundation of China (NSFC) Key Projects (Nos. 81130046; NSFC 81171993 and 81272415); and Guangxi Key Project (No. 2013GXNSFEA053004).

\section{Competing interests}

The authors declare that they have no competing interests.

Received: 30 August 2016 Accepted: 9 March 2017

Published online: 14 March 2017

\section{References}

1. Keller ET, Li LY. The first Tianjin, China forum on tumor microenvironment. Cancer Res. 2011:71(2):310-3. doi:10.1158/0008-5472.CAN-10-2930.

2. Huang Y, Yuan J, Righi E, Kamoun WS, Ancukiewicz M, Nezivar J, et al. Vascular normalizing doses of antiangiogenic treatment reprogram the immunosuppressive tumor microenvironment and enhance immunotherapy. Proc Natl Acad Sci USA. 2012;109(43):17561-6. doi:10.1073/ pnas.1215397109.

3. Keller ET, Zhang J, Cooper CR, Smith PC, McCauley LK, Pienta KJ, et al. Prostate carcinoma skeletal metastases: cross-talk between tumor and bone. Cancer Metastasis Rev. 2001:20(3-4):333-49.

4. Niu YN, Xia SJ. Stroma-epithelium crosstalk in prostate cancer. Asian J Androl. 2009;11(1):28-35. doi:10.1038/aja.2008.39.

5. Yoneda T, Hiraga T. Crosstalk between cancer cells and bone microenvironment in bone metastasis. Biochem Biophys Res Commun. 2005:328(3):679-87. doi:10.1016/j.bbrc.2004.11.070

6. Omabe M, Ezeani M. Infection, inflammation and prostate carcinogenesis. Infect Genet Evol. 2011. doi:10.1016/j.meegid.2011.03.002.

7. Vasto S, Carruba G, Candore G, Italiano E, Di Bona D, Caruso C. Inflammation and prostate cancer. Future Oncol. 2008:4(5):637-45. doi:10.2217/14796694.4.5.637.

8. Teng MW, Ritchie DS, Neeson P, Smyth MJ. Biology and clinical observations of regulatory T cells in cancer immunology. Curr Top Microbiol Immunol. 2010. doi:10.1007/82_2010 50.

9. Miller AM, Lundberg K, Ozenci V, Banham AH, Hellstrom M, Egevad L, et al. $\mathrm{CD}^{+}{ }^{+} \mathrm{CD} 25^{\text {high }} \mathrm{T}$ cells are enriched in the tumor and peripheral blood of prostate cancer patients. J Immunol. 2006;177(10):7398-405.

10. Sfanos KS, Bruno TC, Maris CH, Xu L, Thoburn CJ, DeMarzo AM, et al. Phenotypic analysis of prostate-infiltrating lymphocytes reveals $\mathrm{TH} 17$ and Treg skewing. Clin Cancer Res. 2008;14(11):3254-61. doi:10.1158/10780432.CCR-07-5164.

11. Kiniwa Y, Miyahara Y, Wang HY, Peng W, Peng G, Wheeler TM, et al. CD8 ${ }^{+}$ Foxp3 ${ }^{+}$regulatory $T$ cells mediate immunosuppression in prostate cancer. Clin Cancer Res. 2007;13(23):6947-58. doi:10.1158/1078-0432. CCR-07-0842.

12. Degl'Innocenti E, Grioni M, Capuano G, Jachetti E, Freschi M, Bertilaccio MT, et al. Peripheral T-cell tolerance associated with prostate cancer is independent from $\mathrm{CD} 4{ }^{+} \mathrm{CD} 25^{+}$regulatory T cells. Can Res. 2008;68(1):292-300. doi:10.1158/0008-5472.CAN-07-2429.

13. Yokokawa J, Cereda V, Remondo C, Gulley JL, Arlen PM, Schlom J, et al. Enhanced functionality of $\mathrm{CD}^{+}{ }^{+} \mathrm{CD} 25$ (high)FoxP3 ${ }^{+}$regulatory T cells in the peripheral blood of patients with prostate cancer. Clin Cancer Res. 2008;14(4):1032-40. doi:10.1158/1078-0432.CCR-07-2056.
14. Akins EJ, Moore ML, Tang S, Willingham MC, Tooze JA, Dubey P. In situ vaccination combined with androgen ablation and regulatory T-cell depletion reduces castration-resistant tumor burden in prostate-specific pten knockout mice. Can Res. 2010;70(9):3473-82. doi:10.1158/00085472.CAN-09-2490.

15. Rakebrandt N, Littringer K, Joller N. Regulatory T cells: balancing protection versus pathology. Swiss Med Wkly. 2016;146:w14343. doi:10.4414/ smw.2016.14343.

16. Young MR. Th17 Cells in protection from tumor or promotion of tumor progression. J Clin Cell Immunol. 2016;7(3):431. doi:10.4172/2155-9899.1000431.

17. Kottke T, Sanchez-Perez L, Diaz RM, Thompson J, Chong H, Harrington $\mathrm{K}$, et al. Induction of hsp70-mediated Th17 autoimmunity can be exploited as immunotherapy for metastatic prostate cancer. Can Res. 2007;67(24):11970-9. doi:10.1158/0008-5472.CAN-07-2259.

18. Derhovanessian E, Adams V, Hahnel K, Groeger A, Pandha H, Ward S, et al. Pretreatment frequency of circulating $\mathrm{IL}-17^{+} \mathrm{CD} 4^{+} \mathrm{T}$-cells, but not Tregs, correlates with clinical response to whole-cell vaccination in prostate cancer patients. Int J Cancer. 2009;125(6):1372-9. doi:10.1002/ijc.24497.

19. Gabrilovich DI, Nagaraj S. Myeloid-derived suppressor cells as regulators of the immune system. Nat Rev Immunol. 2009;9(3):162-74. doi:10.1038/ nri2506.

20. Gao D, Mittal V. The role of bone-marrow-derived cells in tumor growth, metastasis initiation and progression. Trends Mol Med. 2009;15(8):333-43. doi:10.1016/j.molmed.2009.06.006.

21. Herroon MK, Rajagurubandara E, Rudy DL, Chalasani A, Hardaway AL, Podgorski I. Macrophage cathepsin K promotes prostate tumor progression in bone. Oncogene. 2013;32(12):1580-93. doi:10.1038/onc.2012.166.

22. Park SI, Liao J, Berry JE, Li X, Koh AJ, Michalski ME, et al. Cyclophosphamide creates a receptive microenvironment for prostate cancer skeletal metastasis. Cancer Res. 2012:72(10):2522-32. doi:10.1158/0008-5472. CAN-11-2928.

23. Park SI, Soki FN, McCauley LK. Roles of bone marrow cells in skeletal metastases: no longer bystanders. Cancer Microenviron. 2011;4(3):23746. doi:10.1007/s12307-011-0081-8.

24. Richardsen E, Uglehus RD, Due J, Busch C, Busund LT. The prognostic impact of M-CSF, CSF-1 receptor, CD68 and CD3 in prostatic carcinoma. Histopathology. 2008;53(1):30-8. doi:10.1111/j.1365-2559.2008.03058.x.

25. Li X, Loberg R, Liao J, Ying C, Snyder LA, Pienta KJ, et al. A destructive cascade mediated by CCL2 facilitates prostate cancer growth in bone. Cancer Res. 2009;69(4):1685-92. doi:10.1158/0008-5472.CAN-08-2164.

26. Hume DA. Differentiation and heterogeneity in the mononuclear phagocyte system. Mucosal Immunol. 2008;1(6):432-41. doi:10.1038/ mi.2008.36.

27. Danilin S, Merkel AR, Johnson JR, Johnson RW, Edwards JR, Sterling JA. Myeloid-derived suppressor cells expand during breast cancer progression and promote tumor-induced bone destruction. Oncoimmunology. 2012;1(9):1484-94. doi:10.4161/onci.21990.

28. Murdoch C, Muthana M, Coffelt SB, Lewis CE. The role of myeloid cells in the promotion of tumour angiogenesis. Nat Rev Cancer. 2008;8(8):61831. doi:10.1038/nrc2444.

29. Mevorach D, Trahtemberg U, Krispin A, Attalah M, Zazoun J, Tabib $A$, et al. What do we mean when we write "senescence," "apoptosis," "necrosis," or "clearance of dying cells"? Ann NY Acad Sci. 2010;1209:1-9. doi:10.1111/j.1749-6632.2010.05774.x

30. Rothlin CV, Lemke G. TAM receptor signaling and autoimmune disease. Curr Opin Immunol. 2010;22(6):740-6. doi:10.1016/j.coi.2010.10.001.

31. Aziz M, Jacob A, Matsuda A, Wang P. Review: milk fat globule-EGF factor 8 expression, function and plausible signal transduction in resolving inflammation. Apoptosis. 2011;16(11):1077-86. doi:10.1007/ s10495-011-0630-0

32. Hanayama R, Tanaka M, Miwa K, Shinohara A, Iwamatsu A, Nagata S. Identification of a factor that links apoptotic cells to phagocytes. Nature. 2002:417(6885):182-7. doi:10.1038/417182a.

33. Selvarajan K, Moldovan L, Chandrakala AN, Litvinov D, Parthasarathy S. Peritoneal macrophages are distinct from monocytes and adherent macrophages. Atherosclerosis. 2011;219(2):475-83. doi:10.1016/j. atherosclerosis.2011.09.014

34. Nakatani H, Aoki N, Nakagawa Y, Jin-No S, Aoyama K, Oshima K, et al. Weaning-induced expression of a milk-fat globule protein, MFG-E8, in mouse mammary glands, as demonstrated by the analyses of its 
mRNA, protein and phosphatidylserine-binding activity. Biochem J. 2006;395(1):21-30. doi:10.1042/BJ20051459.

35. Yang C, Hayashida T, Forster N, Li C, Shen D, Maheswaran S, et al. The integrin alpha(v)beta(3-5) ligand MFG-E8 is a p63/p73 target gene in triple-negative breast cancers but exhibits suppressive functions in ER(+) and erbB2(+) breast cancers. Cancer Res. 2011;71(3):937-45. doi:10.1158/0008-5472.CAN-10-1471.

36. Soki FN, Cho SW, Kim YW, Jones JD, Park SI, Koh AJ, et al. Bone marrow macrophages support prostate cancer growth in bone. Oncotarget. 2015;6(34):35782-96. doi:10.18632/oncotarget.6042.

37. Ershler WB, Harman SM, Keller ET. Immunologic aspects of osteoporosis. Dev Comp Immunol. 1997;21 (6):487-99.

38. Culig Z, Puhr M. Interleukin-6: a multifunctional targetable cytokine in human prostate cancer. Mol Cell Endocrinol. 2011. doi:10.1016/j. mce.2011.05.033.

39. George DJ, Halabi S, Shepard TF, Sanford B, Vogelzang NJ, Small EJ, et al. The prognostic significance of plasma interleukin-6 levels in patients with metastatic hormone-refractory prostate cancer: results from cancer and leukemia group B 9480. Clin Cancer Res. 2005;11(5):1815-20.

40. Alcover J, Filella X, Luque P, Molina R, Izquierdo L, Auge JM, et al. Prognostic value of IL-6 in localized prostatic cancer. Anticancer Res. 2010:30(10):4369-72.

41. Stark JR, Li H, Kraft P, Kurth T, Giovannucci EL, Stampfer MJ, et al. Circulating prediagnostic interleukin-6 and C-reactive protein and prostate cancer incidence and mortality. Int J Cancer. 2009;124(11):2683-9. doi:10.1002/ijc.24241.

42. Chung TD, Yu JJ, Spiotto MT, Bartkowski M, Simons JW. Characterization of the role of IL-6 in the progression of prostate cancer. Prostate. 1999:38(3):199-207.

43. Alberti C. Neuroendocrine differentiation in prostate carcinoma: focusing on its pathophysiologic mechanisms and pathological features. II Giornale di chirurgia. 2010;31(11-12):568-74.

44. Lee GT, Kwon SJ, Lee JH, Jeon SS, Jang KT, Choi HY, et al. Macrophages induce neuroendocrine differentiation of prostate cancer cells via BMP6IL6 Loop. Prostate. 2011. doi:10.1002/pros.21369.

45. Smith ND, Schulze-Hoepfner FT, Veliceasa D, Filleur S, Shareef S, Huang $\mathrm{L}$, et al. Pigment epithelium-derived factor and interleukin-6 control prostate neuroendocrine differentiation via feed-forward mechanism. J Urol. 2008;179(6):2427-34. doi:10.1016/j.juro.2008.01.081.

46. Okamoto M, Lee C, Oyasu R. Autocrine effect of androgen on proliferation of an androgen-responsive prostatic carcinoma cell line, LNCaP: role of interleukin-6. Endocrinology. 1997;138:5071-4.

47. Qiu Y, Ravi L, Kung HJ. Requirement of ErbB2 for signalling by interleukin-6 in prostate carcinoma cells. Nature. 1998;393(6680):83-5.

48. Wallner L, Dai J, Escara-Wilke J, Zhang J, Yao Z, Lu Y, et al. Inhibition of interleukin-6 with CNTO328, an anti-interleukin-6 monoclonal antibody, inhibits conversion of androgen-dependent prostate cancer to an androgen-independent phenotype in orchiectomized mice. Cancer Res. 2006;66(6):3087-95.

49. Culig Z, Steiner H, Bartsch G, Hobisch A. Interleukin-6 regulation of prostate cancer cell growth. J Cell Biochem. 2005;95(3):497-505.

50. Chung TD, Yu JJ, Kong TA, Spiotto MT, Lin JM. Interleukin-6 activates phosphatidylinositol-3 kinase, which inhibits apoptosis in human prostate cancer cell lines. Prostate. 2000;42(1):1-7.

51. Lee SO, Lou W, Johnson CS, Trump DL, Gao AC. Interleukin-6 protects LNCaP cells from apoptosis induced by androgen deprivation through the Stat3 pathway. Prostate. 2004;60(3):178-86.

52. Corey E, Quinn JE, Buhler KR, Nelson PS, Macoska JA, True LD, et al. LuCaP 35: a new model of prostate cancer progression to androgen independence. Prostate. 2003;55(4):239-46.

53. Smith PC, Keller ET. Anti-interleukin-6 monoclonal antibody induces regression of human prostate cancer xenografts in nude mice. Prostate. 2001;48:47-53.

54. Rojas A, Liu G, Coleman I, Nelson PS, Zhang M, Dash R, et al. IL-6 promotes prostate tumorigenesis and progression through autocrine cross-activation of IGF-IR. Oncogene. 2011. doi:10.1038/onc.2010.605.

55. Roca H, Varsos ZS, Sud S, Craig MJ, Ying C, Pienta KJ. CCL2 and interleukin-6 promote survival of human CD $11 \mathrm{~b}^{+}$peripheral blood mononuclear cells and induce M2-type macrophage polarization. J Biol Chem. 2009;284(49):34342-54. doi:10.1074/jbc.M109.042671.
56. Dorff TB, Goldman B, Pinski JK, Mack PC, Lara PN Jr, Van Veldhuizen PJ $\mathrm{Jr}$, et al. Clinical and correlative results of SWOG S0354: a phase II trial of CNTO328 (siltuximab), a monoclonal antibody against interleukin-6, in chemotherapy-pretreated patients with castration-resistant prostate cancer. Clin Cancer Res. 2010;16(11):3028-34. doi:10.1158/1078-0432. CCR-09-3122.

57. Cavarretta IT, Neuwirt H, Zaki MH, Steiner H, Hobisch A, Nemeth JA, et al. MCl-1 is regulated by IL- 6 and mediates the survival activity of the cytokine in a model of late stage prostate carcinoma. Adv Exp Med Biol. 2008;617:547-55. doi:10.1007/978-0-387-69080-3_56.

58. Walsh MC, Choi Y. Biology of the RANKL-RANK-OPG system in immunity, bone, and beyond. Front Immunol. 2014;5:511. doi:10.3389/ fimmu.2014.00511.

59. O'Brien CA, Nakashima T, Takayanagi H. Osteocyte control of osteoclastogenesis. Bone. 2013;54(2):258-63. doi:10.1016/j.bone.2012.08.121.

60. Sabbota AL, Kim HR, Zhe X, Fridman R, Bonfil RD, Cher ML. Shedding of RANKL by tumor-associated MT1-MMP activates Src-dependent prostate cancer cell migration. Can Res. 2010;70(13):5558-66. doi:10.1158/00085472.CAN-09-4416.

61. Yasuda H, Shima N, Nakagawa N, Mochizuki SI, Yano K, Fujise N, et al. Identity of osteoclastogenesis inhibitory factor (OCIF) and osteoprotegerin (OPG): a mechanism by which OPG/OCIF inhibits osteoclastogenesis in vitro. Endocrinology. 1998;139(3):1329-37.

62. Lacey DL, Timms E, Tan HL, Kelley MJ, Dunstan CR, Burgess T, et al. Osteoprotegerin ligand is a cytokine that regulates osteoclast differentiation and activation. Cell. 1998;93(2):165-76.

63. Dougall WC, Glaccum M, Charrier K, Rohrbach K, Brasel K, De Smedt T, et al. RANK is essential for osteoclast and lymph node development. Genes Dev. 1999:13(18):2412-24.

64. Kong YY, Boyle WJ, Penninger JM. Osteoprotegerin ligand: a common link between osteoclastogenesis, lymph node formation and lymphocyte development. Immunol Cell Biol. 1999;77(2):188-93.

65. Simonet WS, Lacey DL, Dunstan CR, Kelley M, Chang MS, Luthy R, et al. Osteoprotegerin: a novel secreted protein involved in the regulation of bone density. Cell. 1997;89(2):309-19.

66. Yang Y, Ma Y, Sheng J, Huang Y, Zhao Y, Fang W, et al. A multicenter, retrospective epidemiologic survey of the clinical features and management of bone metastatic disease in China. Chin J Cancer. 2016;35:40. doi:10.1186/s40880-016-0102-6.

67. Atkins GJ, Haynes DR, Graves SE, Evdokiou A, Hay S, Bouralexis S, et al. Expression of osteoclast differentiation signals by stromal elements of giant cell tumors. J Bone Miner Res. 2000;15(4):640-9.

68. Brown JM, Corey E, Lee ZD, True LD, Yun TJ, Tondravi M, et al. Osteoprotegerin and rank ligand expression in prostate cancer. Urology. 2001;57(4):611-6.

69. Chen G, Sircar K, Aprikian A, Potti A, Goltzman D, Rabbani SA. Expression of RANKL/RANK/OPG in primary and metastatic human prostate cancer as markers of disease stage and functional regulation. Cancer. 2006;107(2):289-98. doi:10.1002/cncr.21978.

70. Perez-Martinez FC, Alonso V, Sarasa JL, Manzarbeitia F, Vela-Navarrete $\mathrm{R}$, Calahorra FJ, et al. Receptor activator of nuclear factor-kappaB ligand (RANKL) as a novel prognostic marker in prostate carcinoma. Histol Histopathol. 2008;23(6):709-15.

71. Zhang J, Dai J, Qi Y, Lin DL, Smith P, Strayhorn C, et al. Osteoprotegerin inhibits prostate cancer-induced osteoclastogenesis and prevents prostate tumor growth in the bone. J Clin Invest. 2001;107(10):1235-44.

72. Morrissey C, Kostenuik PL, Brown LG, Vessella RL, Corey E. Host-derived RANKL is responsible for osteolysis in a C4-2 human prostate cancer xenograft model of experimental bone metastases. BMC cancer. 2007;7:148. doi:10.1186/1471-2407-7-148

73. Zhang J, Dai J, Yao Z, Lu Y, Dougall W, Keller ET. Soluble receptor activator of nuclear factor kappaB Fc diminishes prostate cancer progression in bone. Cancer Res. 2003;63(22):7883-90.

74. Luger NM, Honore P, Sabino MA, Schwei MJ, Rogers SD, Mach DB, et al. Osteoprotegerin diminishes advanced bone cancer pain. Cancer Res. 2001:61(10):4038-47.

75. Honore P, Luger NM, Sabino MA, Schwei MJ, Rogers SD, Mach DB, et al. Osteoprotegerin blocks bone cancer-induced skeletal destruction, skeletal pain and pain-related neurochemical reorganization of the spinal cord. Nat Med. 2000;6(5):521-8. 
76. Armstrong AP, Miller RE, Jones JC, Zhang J, Keller ET, Dougall WC. RANKL acts directly on RANK-expressing prostate tumor cells and mediates migration and expression of tumor metastasis genes. Prostate. 2008;68(1):92-104.

77. Holen I, Croucher PI, Hamdy FC, Eaton CL. Osteoprotegerin (OPG) is a survival factor for human prostate cancer cells. Cancer Res. 2002;62(6):1619-23.

78. Fizazi K, Lipton A, Mariette X, Body JJ, Rahim Y, Gralow JR, et al. Randomized phase II trial of denosumab in patients with bone metastases from prostate cancer, breast cancer, or other neoplasms after intravenous bisphosphonates. J Clin Oncol. 2009;27(10):1564-71. doi:10.1200/ JCO.2008.19.2146

79. Muir VJ, Scott LJ. Denosumab: in cancer treatment-induced bone loss. BioDrugs Clin Immunother Biopharm Gene Ther. 2010;24(6):379-86 doi:10.2165/11203310-000000000-00000.

80. Smith MR, Egerdie B, Hernandez Toriz N, Feldman R, Tammela TL, Saad $F$, et al. Denosumab in men receiving androgen-deprivation therapy for prostate cancer. N Engl J Med. 2009;361(8):745-55. doi:10.1056/ NEJMoa0809003.

81. Fizazi K, Carducci M, Smith M, Damiao R, Brown J, Karsh L, et al. Denosumab versus zoledronic acid for treatment of bone metastases in men with castration-resistant prostate cancer: a randomised, double-blind study. Lancet. 2011;377(9768):813-22. doi:10.1016/ S0140-6736(10)62344-6.

82. Ignatoski KM, Escara-Wilke JF, Dai JL, Lui A, Dougall W, Daignault S, et al. RANKL inhibition is an effective adjuvant for docetaxel in a prostate cancer bone metastases model. Prostate. 2008;68(8):820-9. doi:10.1002/ pros.20744.

83. Zhang J, Lu Y, Dai J, Yao Z, Kitazawa R, Kitazawa S, et al. In vivo realtime imaging of TGF-beta-induced transcriptional activation of the RANK ligand gene promoter in intraosseous prostate cancer. Prostate. 2004;59(4):360-9. doi:10.1002/pros.20019.

84. Kim J, Lahl K, Hori S, Loddenkemper C, Chaudhry A, deRoos P, et al. Cutting edge: depletion of Foxp $3^{+}$cells leads to induction of autoimmunity by specific ablation of regulatory T cells in genetically targeted mice. J Immunol. 2009;183(12):7631-4. doi:10.4049/jimmunol.0804308.

85. Lissbrant IF, Stattin P, Wikstrom P, Damber JE, Egevad L, Bergh A. Tumor associated macrophages in human prostate cancer: relation to clinicopathological variables and survival. Int J Oncol. 2000;17(3):445-51.

86. Nonomura N, Takayama H, Nakayama M, Nakai Y, Kawashima A, Mukai M, et al. Infiltration of tumour-associated macrophages in prostate biopsy specimens is predictive of disease progression after hormonal therapy for prostate cancer. BJU Int. 2010. doi:10.1111/j.1464-410X.2010.09804.x.

87. Soki FN, Koh AJ, Jones JD, Kim YW, Dai J, Keller ET, et al. Polarization of prostate cancer-associated macrophages is induced by milk fat globule-EGF factor 8 (MFG-E8)-mediated efferocytosis. J Biol Chem. 2014;289(35):24560-72. doi:10.1074/jbc.M114.571620.

88. Wong CP, Bray TM, Ho E. Induction of proinflammatory response in prostate cancer epithelial cells by activated macrophages. Cancer Lett. 2009;276(1):38-46. doi:10.1016/j.canlet.2008.10.025.

\section{Submit your next manuscript to BioMed Central and we will help you at every step:}

- We accept pre-submission inquiries

- Our selector tool helps you to find the most relevant journal

- We provide round the clock customer support

- Convenient online submission

- Thorough peer review

- Inclusion in PubMed and all major indexing services

- Maximum visibility for your research

Submit your manuscript at www.biomedcentral.com/submit 